\title{
"Vou crescer sabendo que tem que respeitar a natureza, os animais e as pessoas": vivências infantis no Parque da Matinha, Bahia
}

\author{
"I will grow up knowing that I have to respect nature, animals and people": Children's \\ experiences in Parque da Matinha, Bahia
}

\section{“Creceré sabiendo que tengo que respetar la naturaleza, los animales y las personas": experiencias infantiles en el Parque da Matinha, Bahía}

\author{
Christiana Cabicieri Profice ${ }^{1}$ \\ Helane de Jesus Coelho ${ }^{2}$ \\ Romari Alejandra Martinez Montaño ${ }^{3}$
}

\begin{abstract}
Resumo
Tratamos das vivências e atitudes ambientais de 55 estudantes de ensino fundamental de duas escolas de Itapetinga, no sul da Bahia, visitantes do Parque Municipal da Matinha (PMM). A investigação teve como objetivo geral analisar a vivência e as atitudes ambientais dos estudantes de ensino fundamental que visitaram o PMM. A coleta dos dados seguiu uma abordagem multimétodos, com observações no parque, registros fotográficos e análise documental. As crianças realizaram um desenho após a visita e foram entrevistadas; também responderam à Escala de Atitudes Ambientais (NEP) adaptada para crianças. Os desenhos, de tendência positivista e antropocêntrica, destacaram os animais e brinquedos do parque, com baixa frequência de elementos vegetais. Na análise das entrevistas há amplas referências normativas e destaques positivos e negativos a animais icônicos como cobras. Esses elementos nos permitiram analisar a vivência das crianças que apontaram os principais problemas do parque e revelaram questões éticas e de cuidados com os animais como principais conhecimentos aprendidos nas visitas. O grupo obteve uma média de 3.77 na escala NEP, indicando atitudes ambientais de tendência ecocêntrica. Consideramos a estratégia multimétodos como adequada para uma aproximação à vivência infantil. Queremos enfatizar a importância das crianças como atores sociais no desenvolvimento de políticas públicas referentes aos ambientes de convivência comunitária.
\end{abstract}

Palavras-chave: Vivências. Experiência em zoo. Atitudes ambientais. Desenhos. Multimétodos.

\begin{abstract}
We deal with environmental experiences and attitudes of 55 elementary school students from two Itapetinga schools in the south of Bahia, visitors of Matinha Municipal Park (PMM), whose main attraction is a zoo. The general objective of the investigation was to analyze the experience and environmental attitudes of elementary school students who visited the PMM. Data collection followed a multi-method approach, with observations in the park, photographic records and documentary analysis. The children made a drawing after the visit and were interviewed; they also responded to the Children's Attitudes Scale (NEP). The drawings brought anthropocentric tendencies, highlighted the animals and toys of the park, with low frequency of vegetal elements. In the analysis of the interviews there are broad normative references and positive and negative highlights to iconic animals such as snakes. These elements allowed us to analyze the experience of children who pointed out the main problems in the park and revealed ethical and care issues with animals as the main knowledge learned in the visits. The group obtained an average of 3.77 on the NEP scale indicating environmental attitudes of ecocentric tendency. We consider the multi-method strategy as adequate for an approach to children's experience. We want to emphasize the importance of children as social actors in the development of public policies regarding community living environments.

Keywords: Experiences. Zoo experience. Environmental attitudes. Drawings. Multi-methods.

\footnotetext{
${ }^{1}$ Professora Titular do Departamento de Filosofia e Ciências Humanas da Universidade Estadual de Santa Cruz/UESC. Pesquisadora e docente no Programa de Desenvolvimento Regional e Meio Ambiente/PRODEMA.

${ }^{2}$ Mestre em Desenvolvimento Regional e Meio Ambiente pela Universidade Estadual de Santa Cruz/UESC.

${ }^{3}$ Professora Plena do Departamento de Filosofia e Ciências Humanas da Universidade Estadual de Santa

Cruz/UESC. Pesquisadora e docente no Programa de Desenvolvimento Regional e Meio Ambiente/PRODEMA.
} 


\section{Resumen}

Abordamos las experiencias y actitudes ambientales de 55 estudiantes de escuelas primarias de dos escuelas de Itapetinga en el sur de Bahía, visitantes del Parque Municipal Matinha (PMM), cuya principal atracción es un zoológico. El objetivo general de la investigación fue analizar la experiencia y las actitudes ambientales de los estudiantes de primaria que visitaron el PMM. La recolección de datos siguió un enfoque de múltiples métodos, con observaciones en el parque, registros fotográficos y análisis documental. Los niños hicieron un dibujo después de la visita y fueron entrevistados; también respondieron a la Escala de Actitudes de los Niños (NEP). Los dibujos trajeron tendencias antropocéntricas, destacaron los animales y juguetes del parque, con baja frecuencia de elementos vegetales. En el análisis de las entrevistas hay amplias referencias normativas y puntos culminantes positivos y negativos para animales icónicos como las serpientes. Estos elementos permitieron analizar la experiencia de niños que señalaron los principales problemas del parque y revelaron cuestiones éticas y de cuidado con los animales como principal conocimiento aprendido en las visitas. El grupo obtuvo un promedio de 3.77 en la escala NEP, lo que indica actitudes ambientales de tendencia ecocéntrica. Consideramos que la estrategia de métodos múltiples es adecuada para un enfoque de la experiencia de los niños. Queremos enfatizar la importancia de los niños como actores sociales en el desarrollo de políticas públicas con respecto a los entornos de vida de la comunidad.

Palabras clave: Vivencias. Experiencia del zoológico Actitudes ambientales Unidad de conservación municipal. Multi-métodos.

\section{Introdução}

Os zoológicos tradicionalmente ocupam uma posição na sociedade semelhante a museus vivos, permitindo às pessoas observar e conhecer animais que, em seu habitat natural, seriam perigosos a tão curta distância. Conforme Tuan (1993), os zoológicos modernos foram fundados a partir de iniciativas científicas, mas mantiveram seu caráter espetacular, exibindo publicamente animais selvagens, porém de uma forma dócil ao ser humano. Desde a fundação do primeiro zoológico no Brasil, o Museu Goeldi, em Belém, no ano de 1895 (SANJAD et al., 2012), o número de estabelecimentos deste gênero se ampliou, sendo cada vez mais utilizados como espaços de educação ambiental e conscientização acerca da importância e vulnerabilidade da vida silvestre.

A Sociedade de Zoológicos do Brasil (SZB) foi fundada em 1977, com o objetivo de fomentar a integração dos zoológicos nacionais e difundir uma nova abordagem de manejo de animais em cativeiro, com ênfase na educação ambiental dos visitantes (COSTA, 2004). Em 1990, quase onze milhões de pessoas visitaram zoológicos em áreas urbanas no território nacional. No ano 2017, dados do Ministério do Turismo reportam trinta milhões de pessoas visitando os 116 zoológicos e aquários no Brasil (OLIVEIRA, 2017; SZB, 2017). Isso mostra a relevância dos zoológicos, no Brasil, como instituições de visitação pública, de forma análoga a outros países, onde representam locais favoritos de visitação familiar e interação social de crianças e adultos (FALK et al., 2010).

Apesar desta expressiva ampliação, tanto de estabelecimentos como de público, existe pouco desenvolvimento científico acerca das experiências dos educadores e visitantes dos zoológicos (TURLEY, 2001; MOSS; ESSON, 2013), particularmente no Brasil. Auricchio (1999) investigou a educação ambiental praticada nos zoológicos nacionais. Dos 87 identificados à época, 41 zoológicos conduziam programas e atividades de educação ambiental, contando com apoio municipal. Barreto, Guimarães e Oliveira (2009) realizaram uma pesquisa, no ano de 2003, com crianças e jovens, em Aracaju (SE). Mais da metade dos entrevistados via o zoológico como local de diversão e lazer, sem muita ênfase no aprendizado.

Galheigo e Santos (2009), trabalhando no zoológico de Salvador (BA), concluíram que os visitantes entrevistados após a visita não reportaram conhecimento da fauna local, indicando a necessidade de acesso a essas informações por parte do grande público. Brandão (2011) 
analisou as expectativas e preferências de crianças visitantes desse mesmo zoológico com relação aos animais que seriam avistados, durante a saída de campo organizada pelo Departamento de Educação Ambiental. Dentre as expectativas, avaliadas por questionário aplicado antes da visita, foi destaque unânime a megafauna, como leões e tigres. Dentre as preferências após o percurso no zoológico, os megavertebrados carismáticos continuaram tendo destaque, mas apareceram araras e macacos como animais importantes nas lembranças infantis, ambos não apenas pela beleza, mas, também, por seu comportamento.

Fonseca e Oliveira (2011) investigaram as concepções de Meio Ambiente dos funcionários e educadores do zoológico de Goiânia (GO); concluíram que o estabelecimento, enquanto espaço não formal de educação, falha em atender à sua função educativa e de formação do sujeito ecológico crítico. Bosa e Araújo (2012) estudaram os comportamentos dos visitantes adultos diante dos recintos de felinos no zoológico de Curitiba (PR). Foram feitas análises tanto da observação espontânea como da participação em atividades de educação ambiental, propostas na ocasião por meio de painéis informativos e banners colocados junto aos recintos. Os autores destacam a receptividade dos participantes às informações disponibilizadas, assim como a eficácia na execução de atividades autoexplicativas de baixo custo. Outra pesquisa conduzida com os educadores ambientais de São Carlos (SP) salientou que os programas de educação ambiental dos zoológicos devem investir no tema da conservação ex situ, bem como na capacitação dos monitores (IARED; TULLIO; OLIVEIRA, 2012).

De modo geral, as pesquisas revelam que as expectativas dos educadores e dos visitantes são bem distintas. Nessa direção, o lazer e a recreação proporcionados no zoológico foram destacados pelos visitantes, de todas as idades, em Porto Alegre (RS), onde apenas uma minoria $(10,60 \%)$ declarou ter ido para ver os animais (OZÓRIO; LUNKES; NOLL, 2014). Uma abordagem crítica e participativa de educação ambiental foi adotada em estudo realizado na Fundação Parque Zoológico de São Paulo (MARTINS; RANCURA, 2016). O objetivo do trabalho era a implementação de um espaço educador voltado para a conservação do mico-leãopreto (Leontopithecus chrysopygus). Para os autores, a educação ambiental crítica deve valorizar a participação dos envolvidos e de seus conhecimentos prévios, criando um ambiente dialógico horizontal e envolvente do qual as pessoas se sentem parte. Leira et al. (2017) enfatizaram o enriquecimento ambiental como estratégia de mitigação dos efeitos do cativeiro sobre o bem-estar e comportamentos das espécies animais, além da pertinência da educação ambiental.

Freitas et al. (2007), em sua investigação no Parque Municipal da Matinha (PMM), local de estudo desta pesquisa, avaliaram a contribuição desse zoológico como instrumento de sensibilização dos visitantes. Para isso, entrevistaram cem visitantes, a maioria do município de Itapetinga-Bahia. Uma alta percentagem dos entrevistados (82\%) vê o PMM como um meio de expor animais que não são comuns na região e mais da metade dos entrevistados (52\%) foram favoráveis à caça ou compra de animais para o zoológico, enquanto 53\% afirmaram que visitariam o PMM mesmo que ali não tivesse animais em exposição. Conforme os autores, esses resultados demonstram que são necessários programas educativos que visem a sensibilização dos visitantes.

Buscando contribuir para a ampliação da discussão do tema, nossa investigação teve por objetivo geral analisar a vivência e as atitudes ambientais dos estudantes de ensino fundamental que visitaram o Parque Municipal da Matinha (PMM), único zoológico do sul/sudoeste da Bahia.

\section{Referencial Teórico}


Adotamos uma abordagem monista, evitando o raciocínio interacionista que parte da ideia de que tanto o ambiente como a criança que o percebe preexistem à interação que se estabelece entre eles (HEFT, 2013). Em alternativa a essa perspectiva dualista, que discrimina pessoa e ambiente constituindo a interação como terceiro elemento, nos apoiamos em uma abordagem monista segundo a qual devemos observar a "relação existente entre a criança e o meio, a vivência da criança" (VIGOTSKI, 2010, p. 686). O conceito de vivência enfatiza a importância em compreender a personalidade e o ambiente da criança como uma unidade, tratase de como a criança vive a situação e se afeta por ela (TOASSA; SOUZA, 2010). Em inglês, esse conceito vigotskiano de vivência foi traduzido a experience (experiência), sendo que esta tradução é discutida por pesquisadores da obra de Vigotski (PRESTES; TUNES, 2012). Neste artigo, vivência e experiência são considerados como equivalentes, desde que respeitada a ideia de um evento no qual não se é possível distinguir a criança que percebe e confere significados e o ambiente no qual ela se encontra.

A experiência humana, em qualquer ambiente de socialização, se compõe de uma variedade de dimensões, incluindo aspectos relativos ao espaço em si, bem como questões sociais, intelectuais e emocionais próprias do indivíduo e do momento específico da visita ao parque (PEKARIK; DOERING; KARNS, 1999). Falk e Dierking (1992) apresentaram uma divisão tríplice da experiência do visitante em museus, que pode ser análoga ao que acontece num zoo: a experiência estaria composta por um contexto pessoal (interesses, motivações e preocupações do visitante), um contexto social (as companhias durante o percurso) e um contexto físico (o espaço em si). Com relação aos zoos, são instituições consideradas inclusivas e com orientação familiar, o que favorece um ambiente de aprendizado e faz deles locais de visita de grupos familiares de múltiplas orientações religiosas e origens sociais (FALK et al., 2007). Os zoológicos representam uma das poucas oportunidades que as pessoas de meios urbanos têm para observar animais ditos selvagens, mesmo num contexto controlado, ao mesmo tempo em que recebem informações sobre conservação da biodiversidade, vivência que não será jamais possível nas interações com animais domésticos (BEARDSWORTH; BRYMAN, 2001).

Kellert e Wilson (1993) afirmam que visitantes de zoológicos demonstram um relevante nível de atitudes humanísticas e são capazes de desenvolver empatia com animais não humanos, mesmo não estando dentro do seu convívio diário. Isso reforça a ideia de que a experiência vivida numa visita ao zoológico predispõe as pessoas a atitudes ambientalistas positivas. Ao contrário, para Souza e Albuquerque (2015), os zoológicos reforçam uma perspectiva antropocêntrica de relação com a natureza e seus seres que podem ser capturados e expostos para a satisfação da curiosidade e deleite.

Nessa direção, os estudos sobre atitudes ambientais têm colaborado na compreensão de como o meio ambiente é percebido e avaliado. As atitudes ambientais podem ser definidas como uma organização de crenças e cognições relacionadas com os afetos favoráveis ou desfavoráveis em relação ao objeto (COELHO; GOUVEIA; MILFONT, 2006). Dunlap e Van Liere (1978) propuseram uma escala nomeada de Escala do Novo Paradigma Ecológico (New Ecological Paradigm Scale - NEP) para avaliar as mudanças de atitudes das pessoas em relação ao ambiente. Com este instrumento, detalhado mais adiante, é possível distinguir sujeitos que se encontram no novo paradigma ecológico, ou seja, motivados a desenvolverem atitudes em prol da proteção do ambiente (conservação e preservação) e conhecem a limitação dos recursos naturais daquelas pessoas que ainda se encontram no antigo paradigma ecológico, no qual predominam concepções e atitudes antropocêntricas, que consideram o crescimento econômico constante como algo positivo para o bem estar de todos os indivíduos, compreendendo a natureza como fonte inesgotável de recursos e a ciência e a tecnologia como forças supremas e incontestáveis (MANOLI; JOHNSON; DUNLAP, 2007). 
É relevante destacar que a escala NEP, como tantos outros instrumentos do gênero que visam avaliar o ambientalismo das pessoas, foi formulada em um contexto de país desenvolvido e industrializado, no qual os ambientes humanos e naturais se encontram num grau notável de afastamento e se distinguem de forma antagônica (CORRAL-VERDUGO; PINHEIRO, 1999). Ainda conforme os autores, em países como o Brasil, as pessoas, em zonas mais ou menos urbanizadas, ainda mantém mais contato com o ambiente natural do que em países industrializados e, deste modo, percebem a interação entre as pessoas e ambientes naturais de forma mais integrada. Em outras palavras, não veem a interferência da humanidade na natureza como algo necessariamente ruim, adotando uma tendência mais conservacionista (os seres humanos e a natureza podem conviver de modo sustentável) do que preservacionista (na qual a presença humana na natureza deve ser eliminada) (CORRAL-VERDUGO; PINHEIRO, 1999).

\section{A pesquisa no PMM}

\section{1 Área de Estudo}

O PMM está localizado no perímetro urbano da cidade de Itapetinga-Bahia, englobando 24.466 hectares (Figura 1), conforme o decreto municipal $n^{\circ}$ 860/1973. O PMM foi fechado à visitação pública, em 2013, mesmo ano em que foi elaborado seu projeto de educação ambiental. Na imagem abaixo podemos ver como o zoológico, atração principal do parque, se organiza espacialmente (Figura 1).

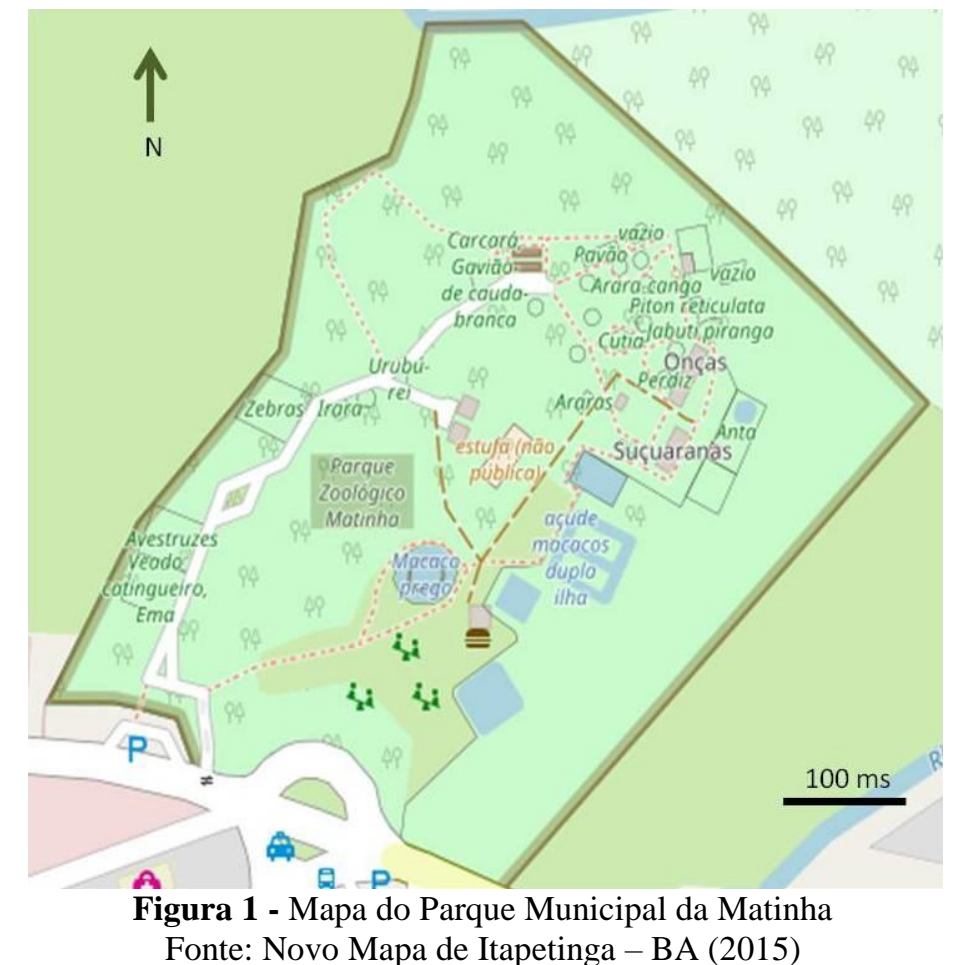

Em 2012, existiam no PMM 42 espécies animais silvestres e exóticos, somando um total de 211 indivíduos distribuídos em três classes: aves, mamíferos e répteis. De aves existiam quarenta e sete indivíduos; mamíferos, sessenta e seis; de répteis, noventa e oito indivíduos. Os anfíbios, aracnídeos e outros animais menores nativos da Mata Atlântica não foram incluídos no censo como parte integrante da coleção de animais existente nas delimitações do PMM. Outro animal que não foi incluído no censo do parque é o urubu preto (Coragyps atratus), espécie observada em vários pontos no PMM. 


\subsection{Participantes}

O estudo foi realizado a partir de amostra composta por 55 estudantes, com idades entre 6 e 15 anos, e professores de duas escolas públicas do ensino fundamental de Itapetinga, uma na zona rural e outra na urbana. Selecionamos duas turmas na escola urbana e uma na escola rural, já que nessa última há apenas uma turma multisseriada. Todos os procedimentos éticos foram adotados e a investigação teve parecer favorável do Comitê de Ética em Pesquisa da Universidade Estadual de Santa Cruz. Os instrumentos e técnicas selecionados nesta pesquisa foram aplicados aos estudantes nas dependências de suas respectivas escolas, nos anos de 2013 e 2014. Optamos por uma perspectiva centrada na criança, onde a exploração sobre o tema do estudo é efetuada em colaboração com os participantes e não sobre eles (PROFICE; PINHEIRO, 2009).

Neste trabalho utilizamos apenas dados produzidos junto às crianças, registro fotográfico e pesquisa documental. Apoiados em pesquisas precedentes que não identificaram, mesmo com uma ampla variação etária, diferenças significativas das respostas entre as crianças menores e maiores (BARRETO; GUIMAR ÃES; OLIVEIRA, 2009), optamos por não considerar as diferenças por idade, tampouco de gênero, localização escolar ou ano de participação na pesquisa.

\subsection{Procedimentos e instrumentos}

A partir da adoção de uma estratégia multimétodos, foram realizadas consultas a documentos, visita in loco, desenhos sobre o PMM, entrevistas e aplicação da escala de atitudes ambientais (NEP). Em todas as ocasiões pedimos aos estudantes que desenhassem o PMM mediante a disponibilização de uma folha de papel quadrado $(21 \times 21 \mathrm{~cm})$ e uma caixa com doze lápis de cores. Para Vigotski [1930]/(2006), a criança emprega o desenho como meio mais eficiente para exprimir seu pensamento. Para esse teórico as crianças, mais que desenhar o que veem, desenham o que conhecem a respeito dos objetos, o que lhes parece mais relevante e não apenas o que enxergam ou imaginam. Assim, por meio de desenhos, representam seus pensamentos, seus conhecimentos e/ou suas interpretações sobre uma dada situação vivida ou imaginada.

Conforme terminavam seus desenhos, os participantes foram entrevistados tanto sobre o que desenharam como para responderem a um questionário de catorze questões sobre a sua experiência no parque, os motivos do fechamento e suas sugestões. Para este trabalho, vamos analisar apenas seis questões, a saber: a) o que lembra do parque; b) três coisas que gostou, c) três coisas que não gostou, d) o que aprendeu, e) três coisas que gostaria de adicionar e f) três coisas que gostaria de retirar do parque. As respostas foram analisadas por meio do software Nvivo 12, que gerou nuvens de palavras, indicando a importância da frequência dos termos mais utilizados pelos participantes em cada resposta.

Após a entrevista, foi aplicada a Escala NEP para crianças (MANOLI; JOHNSON; DUNLAP, 2007). A mesma consta de dez afirmações com uma ordem de distribuição das mesmas e um vocabulário adaptado para esse público. Conforme esse instrumento (do tipo Likert) que varia entre 0 e 5, a pessoa que obtém uma média acima de 3,0 pontos está inserida no novo paradigma ecológico, se alcançar uma média abaixo de 3,0 pontos, suas concepções estão no antigo paradigma ecológico e, caso obtenha exatamente 3,0 pontos na média, não está inserida em nenhuma das concepções ou paradigmas. Vale sinalizar que a escala NEP adaptada 
para crianças limita a idade dessas entre dez e doze anos; contudo, em nosso estudo, ela foi aplicada a todos os participantes.

\section{Resultados}

\subsection{Informação demográfica}

Dos 55 participantes, 25 foram meninas $(45,5 \%)$ e 30 foram meninos $(54,4 \%)$. A média de idade entre os estudantes das três turmas foi de dez anos $(\mathrm{DP}=1,74)$, contudo, parte importante dos estudantes (76\%), se encontra na faixa de dez a doze anos.

\subsection{O PMM desenhado}

Nas análises dos desenhos encontramos uma média de 14,4 elementos por participante. Quando inventariamos os elementos desenhados (animais, vegetais, humanos, celestes e artificiais), os animais estão frequentes em $96,6 \%$ dos desenhos. Os estudantes desenharam o zoológico conforme ele é vivenciado, revelando nos desenhos a ênfase nos animais em detrimento da mata, que é paisagisticamente dominante. Os répteis foram mais enfatizados, sendo os mais frequentes a cobra, em $62 \%$ dos desenhos, seguida do jacaré, em 23,5\%, jabuti, em $12,8 \%$ e outros, em $1,7 \%$. As aves apareceram em 53,4\% dos desenhos. As especificadas pelos estudantes foram: águia, avestruz, arara azul, pavão, urubu rei, ema, falcão, papagaio, tucano, pica-pau e urubu, somando um total de onze diferentes espécies. Os mamíferos mais desenhados foram o leão, em 41,37\% dos trabalhos; o macaco, em 39,60\%, seguido da zebra, em $18 \%$ e outros mamíferos, em $1,03 \%$ das obras. Os insetos representados foram as borboletas, em 6,8\% dos desenhos. Em 5,17\%, foram desenhados animais domésticos. Ao todo foram destacadas 39 espécies animais, excluindo as generalizações como aves e pássaros. Desse total, $79,5 \%$ são animais do PMM. É possível perceber nos desenhos e nas narrativas das crianças que elas são capazes de discriminar os animais que fazem parte da coleção faunística do PMM dos que não fazem.

Os vegetais foram desenhados pela maioria dos estudantes (87,93\%), representados por árvores, flores e capim, sendo as árvores o elemento mais frequente nas obras. Em sua maioria $(73,33 \%)$, não foram especificadas as espécies vegetais e encontramos muitos pés desenhados com uns frutos arredondados e vermelhos, semelhando maçãs (inexistentes na região). Os elementos vegetais desenhados foram descritos pelas crianças apenas como mato, pé de flor, árvore que dá fruta ou apenas árvore. Ressaltamos que no PMM existem muitas árvores, entretanto os estudantes desenharam elementos vegetais isolados que não retratam a Mata Atlântica local. Podemos, aqui, reconhecer o efeito cegueira vegetal, caracterizado pela incapacidade de reconhecer a importância das plantas para a vida nos ecossistemas (BOWKER, 2007). Os humanos estão presentes em $31,1 \%$ dos trabalhos das crianças.

Conforme a descrição de Wallace (treze anos) estão presentes no desenho zebra, macaco, árvore, tartaruga, jacaré, falcão, cobra, leão, estrada, os animais brincando, portões de entrada, brinquedos e vários meninos brincando (Figura 2). 


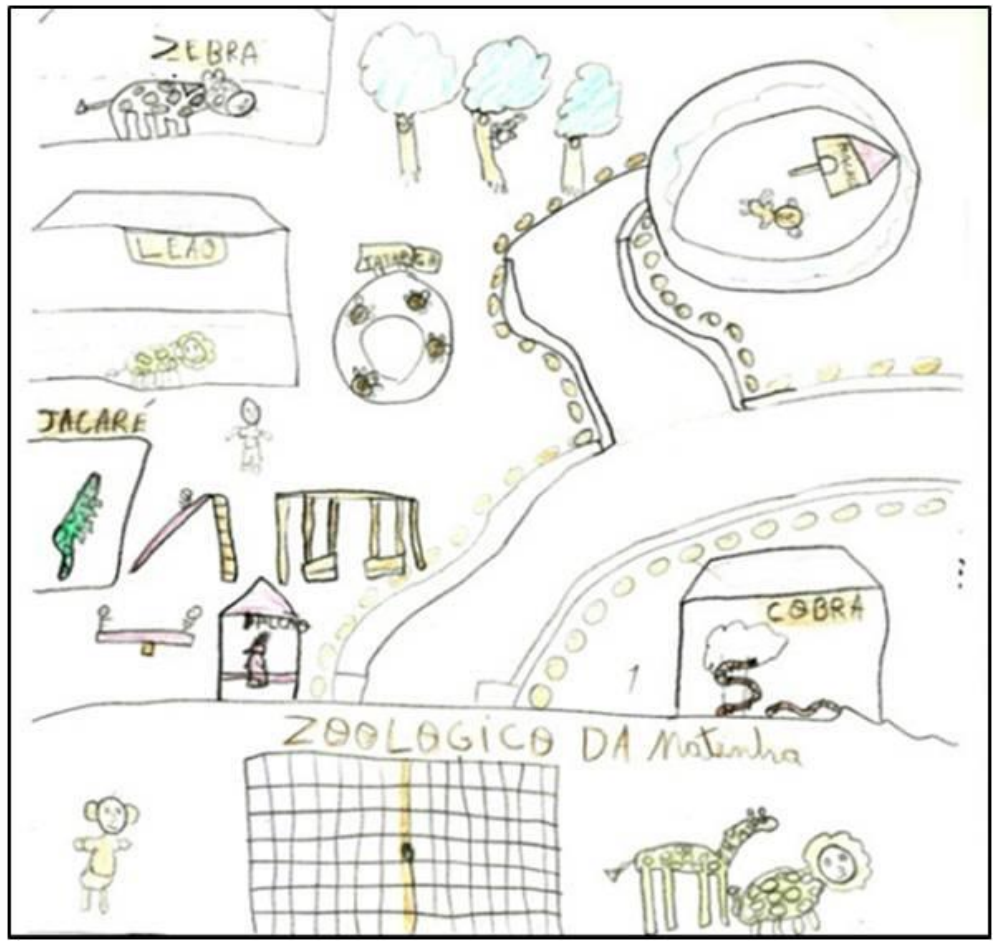

Figura 2 - Wallace, 13 anos

Fonte: Dados de Pesquisa (2013)

No desenho de Alisson podemos observar os recintos com os animais, uma árvore, alguns brinquedos e o campo de futebol (Figura 3).

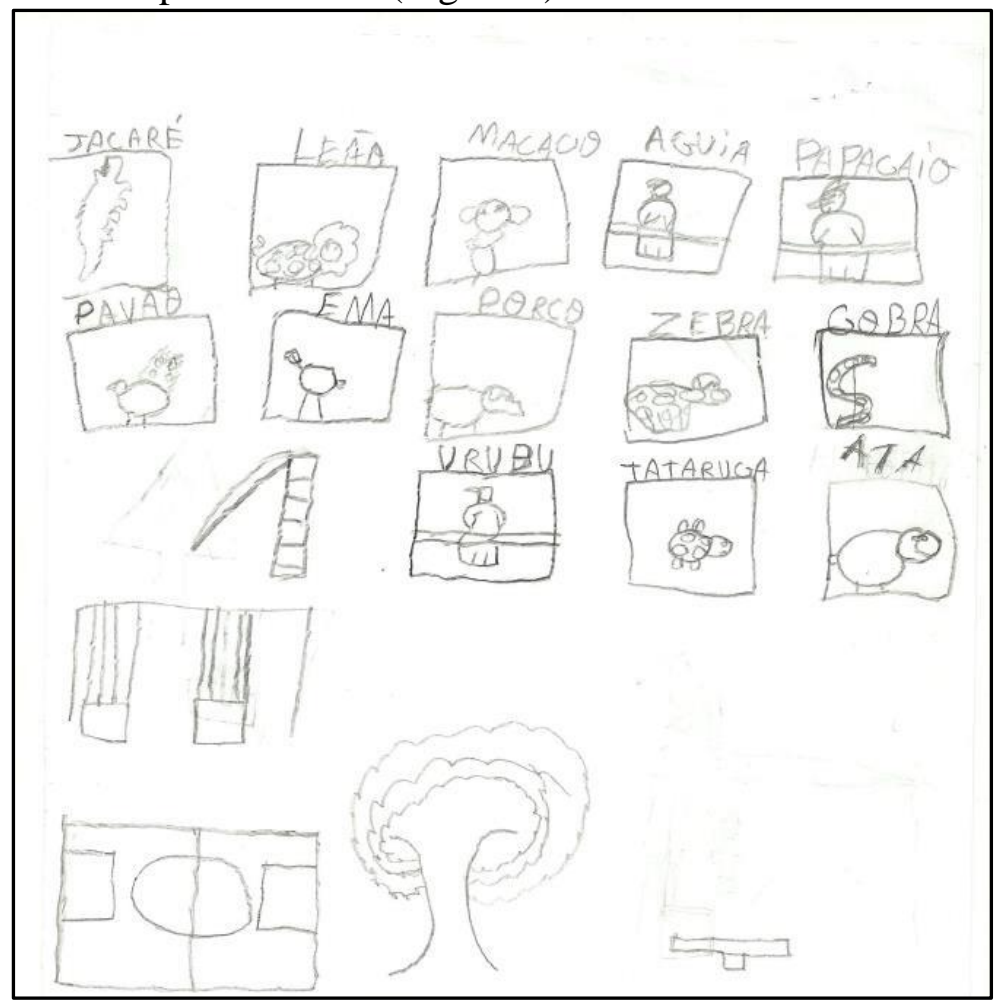

Figura 3 - Alisson, 12 Anos

Fonte: Dados de Pesquisa (2013)

O zoológico de Amanda mais parece com um quintal, onde o leão passeia enquanto alguém dorme tranquilo na rede (Figura 4). 


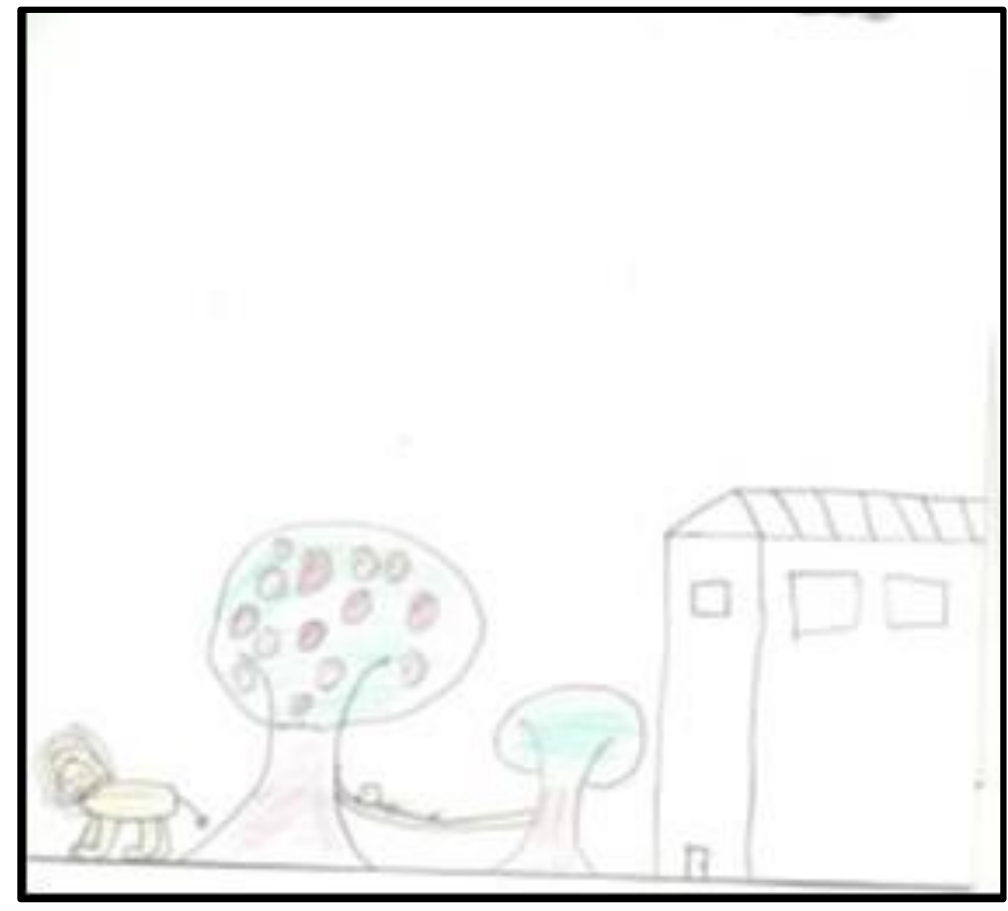

Figura 4 - Amanda, 9 Anos

Fonte: Dados de Pesquisa (2013)

Na Figura 5, temos o desenho apresentado por Raíssa, de oito anos. Seu zoológico, está cheio de famílias de composições diferentes, todas apreciando aos animais enjaulados, inclusive interagindo com eles fisicamente. Não há medo nessas pessoas que os impulsione a tomar distância das jaulas; os animais são, aparentemente, mansos ao ponto de se deixar tocar. Cabe destacar que essa não é necessariamente a realidade do PMM, onde muitos dos animais são, de fato, perigosos se tocados ou importunados.

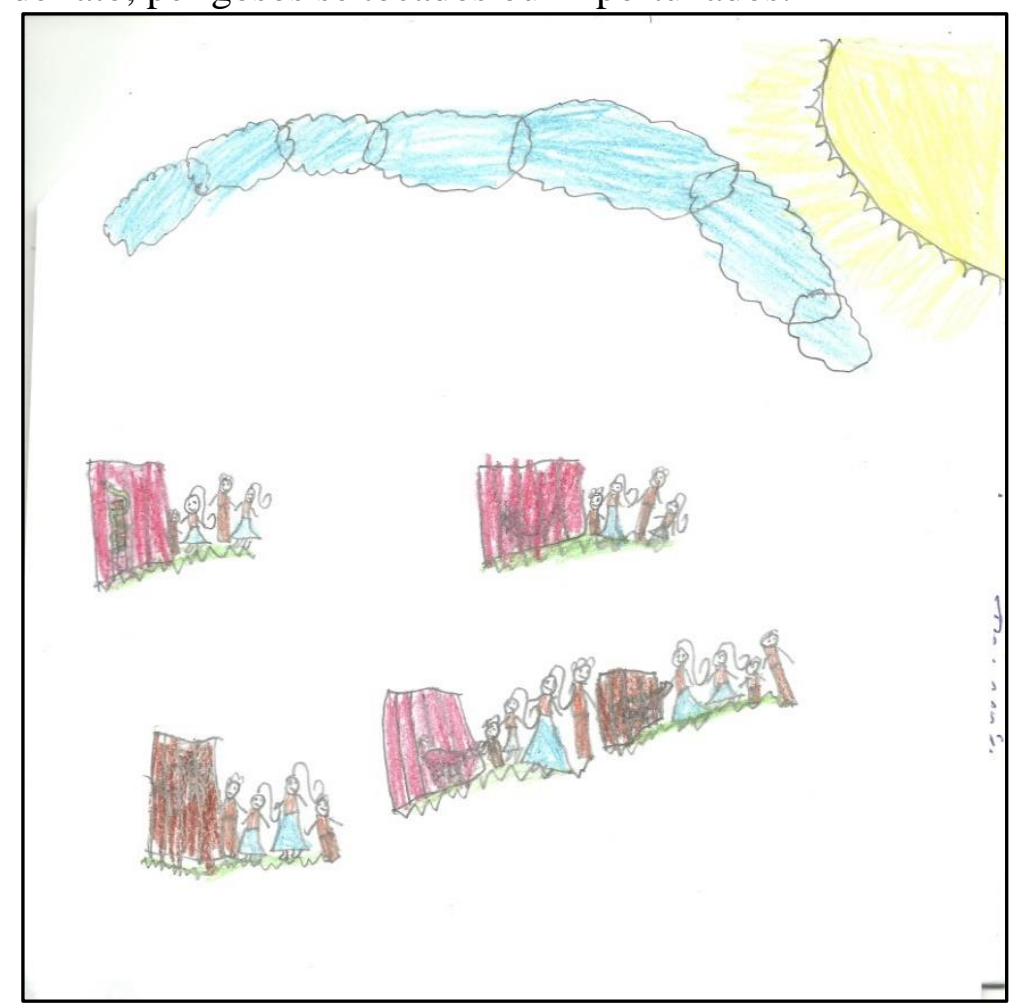

Figura 5 - Raíssa, 8 Anos

Fonte: Dados de Pesquisa (2013) 


\subsection{Entrevistas}

As respostas dadas às perguntas foram analisadas em seu conteúdo e representadas na nuvem de palavras, conforme a importância denotada pela frequência com que aparecem no conjunto das entrevistas analisadas (Figura 6).
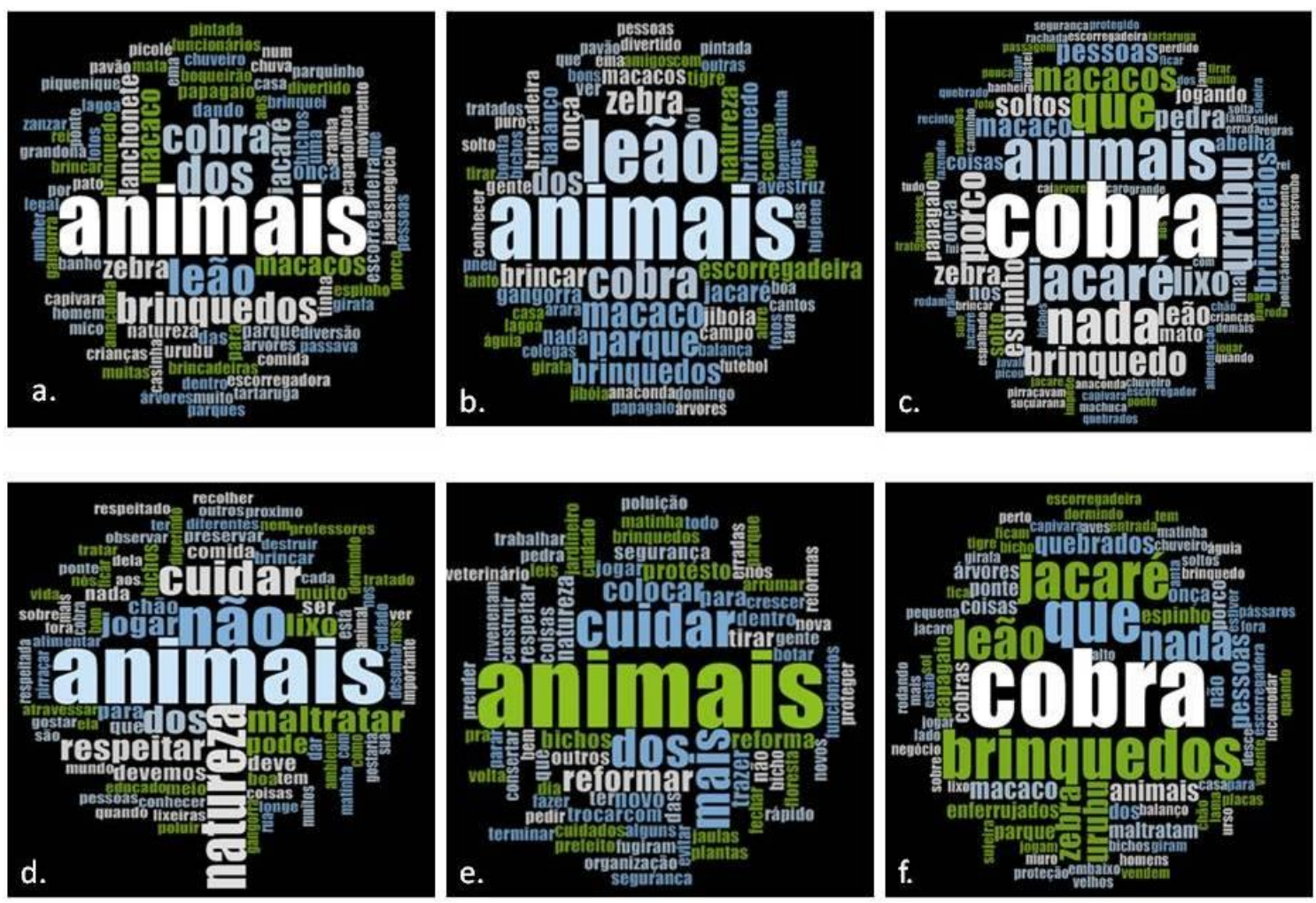

Figura 6 - Nuvens de palavras da importância de frequência no conjunto das entrevistas ${ }^{4}$

Fonte: Dados de Pesquisa (2013)

Trazemos, aqui, falas dos participantes que personificam os resultados exibidos na Figura 6. Como vemos no quadro a., o que mobiliza as crianças como principal lembrança do parque são os animais. Comportamentos humanos inadequados são muito destacados, por exemplo, a fala de Fernanda, de cinco anos: "Vi os bichos e vi uma mulher dando picolé para o macaco e para a zebra" (FERNANDA, 2013, s/p) ${ }^{5}$.

Em relação às coisas de que gostaram e não gostaram do parque (Figura 6, quadros b. e c.) ainda os animais são o foco central e o leão tem destaque entre as preferências das crianças. Entre as coisas que não gostaram, os animais também são predominantes, mas a cobra é, sem dúvida, quem mais desagradou os visitantes. Alguns participantes listaram, entre as coisas que não gostaram, o fato de os animais não estarem em jaulas, como no caso das cobras, cujo recinto é um fosso de aproximadamente 5 metros de profundidade. Isso fica explícito na fala de um dos sujeitos da pesquisa, de doze anos: "Animais soltos, mato muito grande, a grade dos macacos (MATEUS, 2013, s/p).

\footnotetext{
${ }^{4}$ Cada quadro representado no desenho refere-se às questões: a. o que você lembra do parque?; b. diga três coisas que você gostou no parque; c. cite três coisas que você não gostou no parque; d. o que você aprendeu no parque?; e. diga três coisas que você gostaria de colocar no parque; f. diga três coisas que você gostaria de retirar do parque. ${ }^{5}$ Pesquisa de Campo. As falas seguintes também foram recolhidas na pesquisa de campo realizada nos anos de 2013 e 2014. Os nomes verdadeiros foram alterados por fictícios.
} 
O estado de conservação dos brinquedos e de seu terreno, além de sua pouca quantidade foram temas de muitas críticas. Na fala de uma participante de nove anos, lemos: "A abelha me picou e quando fui brincar no escorregador me sujei na lama e caí" (AMANDA, 2013, s/p); no excerto de outra participante de dez anos: "Caro demais as coisas lá e esse brinquedo que machuca" (BIANCA, 2013, s/p). As lanchonetes e os banheiros também foram objetos de crítica por parte das crianças. A restrição de acesso às trilhas e sua péssima conservação e indicação também estão entre as reclamações. Questões referentes à segurança estavam entre as coisas de que não gostaram, como destaca a frase do participante, de catorze anos: "Ficar perdido na trilha, banheiro sujo" (RAMON, 2013, s/p).

Em relação aos conhecimentos aprendidos no parque (Figura 6, quadro d.) identificamos que estes estão, na maioria das vezes, vinculados aos cuidados com os animais e com a limpeza e ordem dos espaços. A frase de um sujeito da pesquisa, de doze anos, deixa isso claro: "Eu vou crescer sabendo que tem que respeitar a natureza, os animais e as pessoas" (MAX, 2013, s/p). Contudo, não encontramos elementos de conhecimento da biodiversidade local; a vegetação do parque não parece ter muita importância na vivência das crianças.

Mesmo aspectos relacionados aos animais expostos são pouco frequentes, rara exceção o trecho a seguir, exposto por participante de onze anos: "Aprendi que a cobra quando está dormindo, ela está digerindo a comida dela (VITOR GABRIEL, 2013, s/p). O elemento água não aparece nas entrevistas, ainda que o rio Catolé, com sérios problemas ambientais, passe pelo parque. Em nenhum momento a Mata Atlântica, enquanto bioma, foi assinalada. Como já indicamos antes, a vegetação da floresta é a grande ausente dos desenhos e falas dos participantes, reforçando a existência de uma cegueira verde (BOWKER, 2007). As crianças declararam ter aprendido que devem respeito aos animais, são cientes da necessidade de cuidados específicos e partidários da condenação aos maus tratos. Muitos mencionaram o aprendizado de alguns comportamentos pró-ambientais, como jogar o lixo na lixeira.

Quanto ao que gostariam de colocar ou retirar do parque, obtivemos uma gama ampla de resposta, com ênfase nos animais mas também nos brinquedos. Rubem, de onze anos "Colocar cobra albina, aquário com escorpião e aranha, tubarão e tigre; Ilana, de dez anos: "Novos animais, brinquedos novos, cuidar mais da natureza $(2013, \mathrm{~s} / \mathrm{p})$. A retirada de um animal, por exemplo, pode estar mais vinculada ao desejo de sua liberdade por parte da criança do que medo ou aversão, como transparece na frase de Iago, de catorze anos: "Tiraria do parque, o jacaré e o macaco, deixava eles livres na mata" e na frase de Rafaely, de onze anos: "colocar novos animais, brinquedos novos, cuidar mais da natureza e tirava brinquedos enferrujados, bichos soltos e bicho valente" (2013, s/p).

Os excertos acima evidenciam, mais uma vez, que a natureza do parque, sobretudo os animais, devam estar sob controle e amansados, bem como as pessoas que têm comportamentos inadequados, como reforça a fala de Rayane, de nove anos: "Tiraria as pessoas que jogam lixo e as pessoas que maltratam os animais". E Max, um dos participantes, de doze anos, propõe sua visão de espaço público com mais acesso e transparência: "Tiraria os brinquedos quebrados, tirar o muro e colocar grade para todo mundo poder olhar (2013, s/p).

\subsection{A escala NEP}

A média da escala NEP calculada para todos os estudantes $(\mathrm{N}=55)$ foi de $3,77(\mathrm{dp}=$ $0,53)$. O teste não revelou diferença estatística significativa na divisão do grupo por sexo ( $[p=$ 0,4772] >0,05). Diante dos dados apresentados 91,4\% do total geral de estudantes têm suas atitudes orientadas por concepções ecocêntricas, ou seja, visam o equilíbrio entre os elementos contidos no ambiente. Este resultado contrasta com o que encontramos nos desenhos, que expressam uma visão mais antropocêntrica, mais ligada ao antigo paradigma ecológico do que ao novo. Aqui, encontramos mais um argumento que reforça a necessidade de atenção aos 
aspectos culturais na aplicação de instrumentos de avaliação de atitudes ambientais formulados em sociedades desenvolvidas e industrializadas.

\section{Discussão}

$\mathrm{Na}$ abordagem vigotskiana, a criança desenha o que sabe de um tema ou objeto e vai representar esse conhecimento de maneira mais ou menos hábil, a depender de sua experiência no desenho e do que julga mais relevante (VIGOTSKI, 2006). Assim, a criança, ao desenhar os animais vistos no zoológico, não está apenas representando aquilo que achou bonitinho ou interessante: encontra-se realizando ligações cognitivas com categorias semânticas que aumentarão seu conhecimento e compreensão do mundo.

Mediante o presente trabalho, podemos afirmar que a criança integra elementos naturais (como leões, zebras e cobras) a elementos fabricados por humanos (brinquedos, quadra de futebol, casa), desse modo o zoológico representa o local onde o natural e o artificial convivem em harmonia; no PMM é possível relaxar numa rede, ainda que na presença de um leão solto (conforme Figura 4, desenho de Amanda, nove anos), o que mostra que esse leão, no parque, está dominado e não representa perigo. Na Figura 5, que traz o desenho da Raissa, de nove anos, as famílias se colocam de cara com animais, os quais mesmo sendo selvagens, estão contidos por elementos de fabricação humana. Contudo, algumas falas das crianças indicavam que os animais soltos no PMM não criavam uma condição segura.

$\mathrm{O}$ que as crianças de Itapetinga nos trazem é uma natureza domada, submissa aos elementos criados pelos humanos (TUAN, 1993). O PMM representa os animais, sim, mas também aquilo que foi feito pelos seres humanos para o lazer das pessoas que o visitam. Assim, o que a criança desenha sobre o PMM representa o que vivenciou em sua visita ao local; isso é extremamente importante, pois alguns autores (MARINO et al., 2010, entre outros) questionam o potencial dos zoológicos como ferramenta de aprendizado. Barreto, Guimarães e Oliveira (2009) concluem que o zoológico de Aracaju (SE) não contribui de forma adequada para o aprendizado dos estudantes. Contudo, não podemos limitar a vivência da criança, nem seu aprendizado, ao que nossos instrumentos podem detectar. Não é porque após a visita o participante não tenha recuperado informações que os educadores consideram relevantes que ele não tenha aprendido nada, ou que o seu aprendizado seja inadequado.

Nos desenhos os animais mais vistos são leão, jacaré, cobra e zebra, que também aparecem em destaque nas entrevistas. Contudo, elementos negativos como lixo ou maltrato aos animais não aparecem representados nos desenhos que, em geral, são de tendência positiva e alegre. Esta tendência em não representar nos desenhos o que lhes desagradou da visita, ou o que consideram como um comportamento inadequado, pode ser atribuída à desejabilidade das crianças em entregar um produto gráfico belo, que suscite admiração e que atenda às expectativas dos solicitantes.

Precisamos, também, destacar que existem dificuldades de ordem técnica em representar a ação e em desenhar animais e humanos em movimento. Não podemos desconsiderar o fato de a disciplina de artes plásticas ter perdido espaço e importância nos currículos escolares, apesar de políticas de educação regionais e locais que a mantém como estrutural de seus projetos políticos pedagógicos. Em escolas que recebem menor investimento nesse sentido, como as que participaram deste estudo, mesmo oportunidades de livre experimentação com diferentes materiais e suportes plásticos são muito raras, o que não promove o desenvolvimento de habilidades de desenho que lhes facilitaria a expressão de suas vivências. Assim, as entrevistas buscam captar o sentido que a criança atribui às suas representações gráficas, e nos permitem ampliar a nossa compreensão da vivência dela.

O público que visita os Jardins Zoológicos chega com um conhecimento prévio, experiências, interesses e motivações para a visita, e seu contexto pessoal. Esses fatores 
influenciam fortemente na aprendizagem das pessoas, muito mais do que variáveis demográficas. O contexto pessoal terá o potencial de prever as mudanças no conhecimento do visitante e sua satisfação com a visita (FALK et al., 2007).

A primeira questão da entrevista teve a intenção de registrar a primeira lembrança do PMM e iniciar o processo de recuperação dessas vivências, seja com a escola ou com a família. Vemos que, de forma marcante, os animais carismáticos mais destacados pela mídia audiovisual mundial vêm como lembrança primordial. Tanto a cobra como o leão são animais carismáticos, icônicos dentro do imaginário infantil. As duas espécies fascinam, por representarem a força e o perigo ao mesmo tempo, e são constantes em fábulas e filmes infantis. $\mathrm{O}$ fato dessas duas criaturas selvagens estarem acessíveis e controladas reforça a sensação de domínio humano sobre as forças naturais. Barreto, Guimarães e Oliveira (2009) também encontram o leão como o favorito das crianças que visitam o zoológico de Aracaju (SE). Leões estiveram entre os animais mais mencionados por crianças de Nebraska e Nova Jersey, nos Estados Unidos, como habitantes das florestas, sem especificar em qual lugar do mundo essas florestas estavam (STROMMEN,1995).

Dentre os elementos desagradáveis, novamente a cobra foi destaque, fazendo jus ao estereótipo de maligno e negativo que esse animal ostenta. Nesse sentido, não podemos ignorar que desde a escola a criança aprende apenas uma visão utilitarista dos animais (SANTOS; BONOTTO, 2012). Visto que as cobras são enxergadas desde uma perspectiva negativa, elas não recebem atenção ou interesse por parte dos educadores no sentido de desmistificar o estereótipo imposto socialmente e que tem contribuído para o risco de extinção de espécies (YOREK, 2009). Ainda que não seja o propósito deste trabalho, destacamos, ainda, o viés religioso desse animal, visto na perspectiva judaico-cristã como a representação do mal, o que faz com que se atribua uma intencionalidade moral nas ações desse animal e o desejo de eliminá-lo de todo local considerado do bem.

As crianças manifestaram incômodo e desaprovação com o estado de conservação do local, em especial dos brinquedos e da área de lazer infantil, frisando enfaticamente a necessidade de reparo de equipamentos quebrados como, por exemplo, o conserto de uma ponte sobre a qual eles não podem andar. Muitos brinquedos estão destroçados, enferrujados ou, ainda, se localizam em terrenos sem boa drenagem e que se encharcam nas chuvas deixando muita lama na área de recreação. Outro problema na área dos brinquedos é a falta de poda de vegetação que acaba por atrapalhar seu uso e pode ocasionar ferimentos.

Palavras como medo, pena, amor, raiva, dor, de cunho mais afetivo, não foram encontradas nas entrevistas. Possivelmente, a ausência desses termos ocorreu em função do conteúdo solicitado pelo instrumento, sem qualquer ênfase em elementos afetivos. Esse é um aspecto importante que não deve estar ausente de investigações que pretendam analisar as vivências infantis com os seres e ambientes naturais.

Percebemos que, quando questionados sobre o que aprenderam durante a visita, aparecem termos carregados de significância ética, como dever, respeito, bem como palavras normativas, como não. As crianças parecem trazer como aprendizado principal que existem regras dentro da instituição, e que essas regras representam uma postura ética do bem: cuidar dos animais, não jogar lixo, respeitar aos animais, não sujar, não maltratar; todas essas expressões acabam por criar parâmetros normativos de conduta que, espera-se, trascendam o PMM e sejam levados para o cotidiano. Infelizmente, atitudes derivadas de conceitos éticos só são internalizadas com a prática; as visitas esporádicas não permitem que as crianças pratiquem, corriqueiramente, os conceitos positivos aprendidos no PMM. O fato da instituição estar fechada desde 2013, sem perspectivas de abertura, coloca maior gravidade no hiato entre ensino e aprendizagem, pois os conceitos, quando não revivenciados, são esquecidos.

Aspectos éticos e normativos aparecem, novamente, como predominantes na resposta a o que retiraria do parque. As crianças, provavelmente, retirariam esses mesmos elementos da 
sociedade: lixo, pessoas mal educadas, brinquedos quebrados, muros altos. O humanismo se revela na forma como nos afetamos pelas condições de vida dos demais seres vivos, como os animais. As crianças de Itapetinga conhecem os problemas do parque e sabem como resolvêlos, só não possuem os meios e recursos. A abordagem centrada na criança propõe que facilitemos a sua voz, em vez de definir o que é melhor para ela.

$O$ resultado da aplicação da escala NEP entre as crianças participantes não trouxe um resultado conclusivo. As crianças de Itapetinga estariam a um meio caminho da direção do novo paradigma ecológico, mas ainda distantes de sua consolidação. Contudo, essa escala tem revelado propriedades psicométricas pouco consistentes quando empregadas em países em desenvolvimento (HAWCROFT; MILFONT, 2010; ZHU; LU, 2017) e no Brasil (BECHTEL; CORRAL-VERDUGO; PINHEIRO, 1999; PIRES et al., 2016). Entre as possíveis explicações para esses resultados, temos a redação das questões analisadas pelos respondentes que podem não ter entendido seu conteúdo ou, ainda, a pouca rigidez na separação entre pessoas e natureza característica dos países em desenvolvimento em contraste com aqueles considerados industrializados. Nessa direção, análises mais profundas da própria escala, bem como de sua recepção em diferentes contextos socioeconômicos, são recomendadas em estudos futuros.

No que concerne à relação entre os desenhos e os questionários, podemos afirmar que ambos os instrumentos captaram elementos comuns, como a importância atribuída tanto aos brinquedos como aos animais. Pessoas (como funcionários e crianças) estão presentes do mesmo modo. Todavia, os desenhos não trazem a mesma riqueza de elementos que as entrevistas. Como já relatamos, eles são de caráter mais estereotípico e trazem representações genéricas como nuvens e sol, árvores com frutas vermelhas, parecendo maçãs, e casas de vários andares (não presentes no PMM). Isto nos leva a concluir que a estratégia multimétodo é certamente a abordagem apropriada para a apreciação de processos complexos como as vivências infantis, pois permitem aos participantes diferentes meios de expressão e reflexão de suas percepções e atitudes diante de determinado ambiente ou tema.

Mesmo assim, buscando uma abordagem metodológica variada, há muito que nos escapa, são as vivências que as crianças tiveram no parque e, ainda, aquelas na escola e na própria atividade de desenho que lhes propusemos. Tanto os desenhos como as entrevistas nos abrem uma janela para essas vivências e o vislumbre do que elas significaram tanto para as crianças, individualmente, como enquanto parte de um grupo local. Entre a vivência vivida e a vivência desenhada ou relatada existem zonas de interface e outras que se desconhecem.

Podemos apenas imaginar suas vivências, baseados nos desenhos e nas falas das crianças e em nossas próprias experiências anteriores em zoológicos, seja como crianças ou como adultos. Quando as visitas são feitas em datas comemorativas, como o Dia das Crianças ou aos domingos, o parque fica repleto de gente e de movimento. Os ambulantes ficam na porta do parque com balões, algodão doce, pipoca. As famílias trazem alimentação ou compram na lanchonete, não raro utilizam seus próprios equipamentos de música para animar a ocasião. Esse ambiente de lazer comunitário contrasta, marcadamente, com as visitas escolares vinculadas a datas relacionadas ao meio ambiente, durante as quais o parque se encontra fechado ao público, recebendo apenas os estudantes e seus professores. Não há ambulantes, nem música e o parque se encontra vazio de gente. As crianças vivenciam o mesmo parque em duas situações, nos trazendo percepções (imagens e palavras) diferentes do mesmo ambiente. Afinal, o parque é para nós ou para os animais?

Como vimos, embora os animais estejam presentes, as pessoas e a presença de objetos humanos parecem ter preponderância, dada a frequência expressiva nos desenhos de casas, redes, quadras de futebol, brinquedos metálicos, todos elementos artificiais, que não condizem com as necessidades dos animais que lá habitam. Porém, as crianças que pouco interferem na gestão do espaço público, devem supor que os adultos fizeram o zoológico atendendo às necessidades dos animais. Como vimos, algumas delas desejam libertar os animais silvestres, 
mas no geral o fato de os animais estarem em recintos para exposição parece ser bastante aceitável.

\section{Considerações finais}

É inegável que a nossa sociedade transita um momento álgido de questionamento das suas próprias bases éticas e normativas. Nessa direção, a crise ambiental que nos circunda faz imprescindível a inclusão da educação ambiental, centrada em valores, na formação das nossas crianças e jovens (GRÜN, 2007; SANTOS; BONOTTO, 2012). A pesquisa, que teve por objetivo analisar a vivência e as atitudes ambientais dos estudantes de ensino fundamental que visitaram o PMM, nos revelou que os participantes criaram suas vivências com relação ao PMM independente das excursões escolares; o espaço é um local preferido por famílias em busca de lazer e, com seu fechamento, a sociedade Itapetinguense perdeu uma possibilidade de interação considerada sadia e familiar, mesmo que estivesse aberto ao público apenas aos domingos. A demanda era enorme, mas o impacto humano também; a falta de recursos e investimentos locais e regionais, a precariedade das instalações, o perigo para a segurança de animais e visitantes, a falta de foco e gerenciamento, tudo contribuiu para o fechamento da instituição, sem data de reabertura. Sabemos da extrema necessidade de ações de preservação e de conservação nessa região, parte do Corredor Central da Mata Atlântica. O PMM é um capital natural, social e cultural, um espaço com predominância de elementos naturais e contexto mais que adequado para a educação ambiental das dezenas de municípios aos quais o PMM prestava serviços.

Dentre as experiências negativas relatadas, as crianças deste estudo, todas na faixa etária pré-adolescente, destacaram a necessidade de espaços separados dos jovens mais velhos, pois a forma de aproveitar o espaço dessas faixas etárias é diferente, havendo interações nem sempre amistosas durante o convívio nos espaços de lazer. Resgatamos, aqui, a forte insatisfação com as condições de preservação dos brinquedos e do terreno, reforçando que esse atrativo fundamental do PMM, deveria ser acessível apenas, na visão dos entrevistados, para as crianças menores, indicando a necessidade de uma área para os adolescentes jovens.

As experiências negativas passaram também pela empatia com os animais, nem sempre em bom estado de saúde ou bem estar, o que mostra que os componentes individuais e emocionais da experiência jogam um papel fundamental na construção do imaginário vivido. As crianças, tradicionalmente consideradas indivíduos sem voz dentro da sociedade, devem ser ouvidas, pois o que eles retirariam do parque é um reflexo de como eles anseiam uma sociedade: sem muros, sem divisões, sem lixo e com felicidade e bem-estar para todos os seres vivos, dentre eles os humanos.

\section{Referências}

AURICCHIO, A. L. R. Potencial da educação ambiental nos zoológicos brasileiros. Publicações Avulsas Instituto Pau Brasil História Natural, São Paulo, v. 1, n. 1, p. 1-48, 1999.

BARRETO, K. F. B.; GUIMARÃES, C.R.P.; OLIVEIRA, I. S. S. O zoológico como recurso didático para a prática de Educação Ambiental. Revista FACED, Salvador, n.15, p. 79-91, Jan./Jul. 2009.

BEARDSWORTH, A.; BRYMAN, A. The wild animal in late modernity: the case of the Disneyization of zoos. Tourist Studies, Londres, v.1, n. 1, p. 83-104, 2001.

BECHTEL, R.; CORRAL-VERDUGO, V.; PINHEIRO, J. Environmental Belief Systems. Journal of Cross-Cultural Psychology, Washington, v.1, n.30, p.122-128, 1999. 
BOSA, C. R.; ARAÚJO, L. de O. Reações comportamentais dos visitantes mediante o recinto dos felinos no zoológico municipal de Curitiba, Paraná. Monografias Ambientais, Santa Maria, v. 10, n. 10, p. 2288-2301, Out./Dez. 2012.

BOWKER, R. Children's perceptions and learning about tropical rainforests: an analysis of their drawings. Environmental Education Research, Stanford, v. 13, n. 1, p. 75-96, 2007.

BRANDÃO, L. R. P.; MARTINEZ, R. A. A Fauna Carismática nativa e exótica, segundo as percepções de alunos que visitaram o Parque Zoobotânico Getúlio Vargas em Salvador-BA, e seu papel como ícone conservacionista. 2011. 180 f. Dissertação (Mestrado em Programa de PósGraduação em Zoologia) - Universidade Estadual de Santa Cruz, Ilhéus, 2011.

COELHO, J. A. P.; GOUVEIA, V. V.; MILFONT, T. L. Valores humanos como explicadores de atitudes ambientais e intenção de comportamento pró-ambiental. Psicologia em Estudo, Maringá, v. 11, n. 1, p. 199-207, Jan./Abr. 2006.

CORRAL-VERDUGO, V.; PINHEIRO, J. Condições para o estudo do comportamento pró-ambiental. Estudos de Psicologia, Natal, v.1, n.4, p. 7-22, 1999.

COSTA, G. de O. Educação Ambiental - experiências dos zoológicos brasileiros. REMEA-Revista Eletrônica do Mestrado em Educação Ambiental, Rio Grande, v. 13, n. 1, p.140-150, 2004.

DUNLAP, R.; VAN LIERE, K. The "new environmental paradigm". The journal of Environmental Education, London, v.9, n.1, p. 10-19, 1978.

FALK, J.; DIERKING, L. The museum experience. Washington, DC: Whalesback Books, 1992.

FALK, J.; H.; REINHARD, E.; VERNON, C.; BRONNENKANT, K.; DEANS; N.; HEIMLICH, J. Why Zoos \& Aquariums Matter: assessing the Impact of a Visit. Association of Zoos \& Aquariums: Silver Spring, MD, 2007.

FALK, J.; HEIMLICH, J. VERNON, C.; BRONNENKANT, K. Critique of a Critique: do Zoos and Aquariums Promote Attitude Change in Visitors? Society and Animals, Leiden, v. 18, n.4, p. 415-419, 2010.

FONSECA, F. S. R.; OLIVEIRA, L. G. Concepções de meio ambiente dos educadores ambientais do Zoológico de Goiânia: implicações nas atividades e contribuições para a formação do sujeito ecológico? Educar em Revista, Curitiba, v. 1, n. 41, p. 231-246, Jul./Set. 2011.

FREITAS, M. S.; SILVA, S. L.; COSTA, E. N.; LESSA, A. O. O Parque Municipal da Matinha como instrumento de sensibilização ambiental. Revista Eletrônica do Mestrado em Educação Ambiental, Rio Grande, v. 19, n.1, p. 235-245, 2007.

GALHEIGO, C. B. de S.; SANTOS, M. de M. Saberes dos visitantes do zoológico de Salvador-BA sobre a fauna nativa e sua conservação. Revista eletrônica Mestrado em Educação Ambiental, Rio Grande, v. 23, n.1, p. 515-530, 2009.

GRÜN, M. Em busca da dimensão ética da educação ambiental. Campinas: Papirus, 2007.

HAWCROFT, L.; MILFONT, T. The Use (and Abuse) of the New Environmental Paradigm Scale Over the Last 30 Years: a Meta-Analysis. Journal of Environmental Psychology, Amsterdam, v.2, n.30, p.143-158, 2010. 
HEFT, H. Environment, cognition, and culture: Reconsidering the cognitive map. Journal of Environmental Psychology, Amsterdam, v. 33, n.1, p. 14-25, 2013.

IARED, V.G.; DI TULLIO, A.; OLIVEIRA, H. T. de. Impressões de Educadoras/es Ambientais em Relação às visitas guiadas em um Zoológico. Revista Eletrônica do Mestrado em Educação Ambiental, Rio Grande, v. 28, n.1, p. 258-263, 2012.

KELLERT, S.; WILSON, E. The biofilia hypothesis. Washington, DC: Island Press, 1993.

LEIRA, M. H.; REGHIM, L. S.; CUNHA, L. T.; ORTIZ, L. S.; PAIVA, C. de O.; BOTELHO, H. A.; CIACCI, L. da S.; BRAZ, M. S.; DIAS, N. P. Bem-estar dos animais nos zoológicos e a bioética ambiental. PUBVET, Londrina, v., n.11, p. 538-645, 2017.

MANOLI, C.; JOHNSON, B.; DUNLAP, R. Assessing children's environmental worldviews: Modifying and validating the New Ecological Paradigm Scale for use with children. The Journal of Environmental Education, Londres, v. 38, n. 4, p. 3-13, 2007.

MARINO, L.; LILIENFELD, S.; MALAMUD, R.; NOBIS, N.; BROGLIO, R. Do Zoos and Aquariums Promote Attitude Change in Visitors? A Critical Evaluation of the American Zoo and Aquarium Study. Society and Animals, Amsterdam, v.1, n. 18, p. 126-138, 2010.

MARTINS, C.; RANCURA, K. G. de O. As metodologias participativas no processo de elaboração de espaços educadores em zoológicos em uma perspectiva de educação ambiental crítica. Revista Eletrônica do Mestrado em Educação Ambiental, Rio Grande, v. 33, n. 1, p. 307-326, 2016.

MOSS, A.; ESSON, M. The educational claims of zoos: where do we go from here? Zoo Biology, São Francisco, v. 1, n.32, p. 13-8, 2013.

OLIVEIRA, N. Turismo pelos zoológicos do Brasil. Brasília: Site do Ministério do turismo. Disponível em: <http://www.turismo.gov.br/últimas-notícias/7996-turismo-pelos-zoológicos-dobrasil.html>. Acesso em: 14 out. 2020.

OZÓRIO, D.; LUNKES, L.; NOLL, M. Lazer em forma de recreação em parques zoológicos: possibilidade interdisciplinar. Cinergis, Santa Cruz do Sul, v. 15, n. 2, p. 75-80, 2014.

PEKARIK, A.; DOERING, Z.; KARNS, D. Exploring Satisfying Experiences in Museums. Curator, Nova Jersey, v.2, n. 42, p.152-173, 1999.

PIRES, P.; RIBAS JUNIOR, R.; HORA, G.; FILGUEIRAS, A.; LOPES, D. Psychometric properties for the Brazilian version of the new ecological paradigm: revised. Temas em Psicologia, Ribeirão Preto, v.4, n.24, p.1407-1419, 2016.

PRESTES, Z.; TUNES, E. A trajetória de obras de Vigotski: um longo percurso até os originais. Estudos de Psicologia, Campinas, v. 4, n. 29, p. 327-340, 2012.

PROFICE, C. C.; PINHEIRO, J. Explorar com crianças - reflexões teóricas e metodológicas para os pesquisadores. Arquivos Brasileiros de Psicologia, Rio de Janeiro, v. 3, n. 61, p. 11-22, 2009.

SANJAD, N.; ORENLL, D. C.; SILVA JUNIOR, J. de S.; HOOGMOED, M. S.; HIGUCHI, H. Documentos para a história do mais antigo jardim zoológico do Brasil: o Parque Zoobotânico do Museu Goeldi. Bol. Mus. Para. Emílio Goeldi. Cienc. Hum., Belém, v. 7, n. 1, p. 197-258, Jan./Abr. 2012. 
SANTOS, J. R.; BONOTTO, D. M.B. Educação ambiental e animais não humanos: linguagens e valores atribuídos por professoras do ensino fundamental. Pesquisa em Educação Ambiental, Rio Claro, v.1, n.7, p. 9-27, 2012.

SOUZA, R. S. de; ALBUQUERQUE, L. Sobre o olhar antropocêntrico: o ser humano e o jardim zoológico. Revista Internacional Interdisciplinar INTERthesis, Florianópolis, v. 12, n. 1, p. 117-129, 2015.

STROMMEN, E. Lions, Tigers and bears, Oh My! Children's conceptions of forests and their inhabitants. Journal of Research in Science Teaching, Nova Iorque, v.3, n.7, p.683-698, 1995.

SOCIEDADE DE ZOOLÓGICOS DO BRASIL - SZB. Zoos e Aquários do Brasil. 2017. Disponível em: <http://www.szb.org.br/zoos-e-aquarios.html > Acesso em 20 jan. 2017.

TOASSA, G.; SOUZA, M. P. R. de. As vivências: questões de tradução, sentidos e fontes epistemológicas no legado de Vigotski. Psicologia USP, São Paulo, v.4, n. 21, p. 757-779, 2010.

TUAN, Y-F. Passing Strange and Wonderful: Aesthetics, Nature, and Culture. Washington DC: Shearwater Books, 1993.

TURLEY, S. Children and the demand for recreational experiences: the case of zoos, Leisure Studies, Londres, v.1, n.20, p.1-18, 2001.

VIGOTSKI, L. S. La imaginación y el arte en la infancia. Madrid: Ediciones Akal, 1930-2006.

VIGOTSKI, L. S. Quarta aula: a questão do meio na pedologia. Tradução de Márcia Pileggi Vinha. Psicologia USP, São Paulo, v. 21, n. 4, p. 681-701, 2010.

YOREK, N. The Only Good Snake is a Dead Snake: Secondary School Students' Attitudes Toward Snakes. Biotechnology \& Biotechnological Equipment, Sofia, v. 23, n. supl., p. 31-35, 2009.

ZHU, X.; LU, C. Re-evaluation of the New Ecological Paradigm scale using item response theory. Journal of Environmental Psychology, Londres, v.1, n.54, p. 79-90, 2017. 